\title{
Professionalism in the Built Heritage Sector
}

\section{Editors}

Koen Van Balen \& Aziliz Vandesande

Raymond Lemaire International Centre for Conservation and Department of Civil Engineering, KU Leuven, Heverlee, Belgium 
Cover illustration: University Library of Ghent, designed by Henry van de Velde in 1933: view of the restored East wing with new entrance and the tower of books under restoration; restoration and actualization by the 'Boekentoren Ontwerpteam': Robbrecht \& Daem Architecten (head architects \& coordination), Barbara Van der Wee Architects (preliminary research \& restoration advice), Daidalos Peutz (building physics), SumProject (technical research \& specifications), Baro Architectuur (follow-up construction site), Greisch Engineering (structural engineering), VK Engineering (Techniques). Photo credit: Geert Roels 2018.

'Reflections on Cultural Heritage Theories and Practices' book series

3. Innovative Built Heritage Models

Edited by Koen Van Balen \& Aziliz Vandesande

ISBN 978-1-138-49861-7 (HB)

ISBN 978-1-351-01479-3 (eBook)

4. Professionalism in the Built Heritage Sector

Edited by Koen van Balen \& Aziliz Vandesande

ISBN 978-0-367-02763-6 (HB)

ISBN 978-0-429-39791-2 (eBook)

CRC Press/Balkema is an imprint of the Taylor \& Francis Group, an informa business

(C) 2019 Taylor \& Francis Group, London, UK

Typeset by V Publishing Solutions Pvt Ltd., Chennai, India

All rights reserved. No part of this publication or the information contained herein may be reproduced, stored in a retrieval system, or transmitted in any form or by any means, electronic, mechanical, by photocopying, recording or otherwise, without written prior permission from the publisher.

Although all care is taken to ensure integrity and the quality of this publication and the information herein, no responsibility is assumed by the publishers nor the author for any damage to the property or persons as a result of operation or use of this publication and/or the information contained herein.

\section{Library of Congress Cataloging-in-Publication Data}

Applied for

Published by: CRC Press/Balkema

Schipholweg 107C, 2316 XC Leiden, The Netherlands

e-mail:Pub.NL@taylorandfrancis.com

www.crcpress.com - www.taylorandfrancis.com 


\section{Table of contents}

Committees

\section{Introduction}

On established built heritage profiles and capacities, the rise of new profession(al)s and the need for training and education to deal with ongoing disruptive changes in the sector

A. Vandesande \& K. Van Balen

\section{Profiles and capacities}

Profession(s) and professional(s) in the conservation process

S. Della Torre \& R. Moioli

Structural conservation engineering in practice: Lessons learned

A. Drougkas \& E. Verstrynge

Building archaeology in Leiden (NL): A practical approach

P.J. De VoS

The role of the professional authority in the monument preservation - changes in the institutional monument preservation system in Hungary between 2011 and 2017

A. Veёreös \& T. Fejérdy

Overview of project governance framework for built heritage conservation in India

D. Roy, S. N. Kalidindi \& A. Menon

The increasing relevance of soft skills in the conservation profession

R. Moioli

Education, training and quality labels

Fostering cooperation in the European Union on skills, training and knowledge transfer in cultural heritage professions

A. Galán-Pérez, I.M. Grumazescu, K. Gunthorpe, A. Limburg, N. Roche, E. Sciacchitano, J. van Leeuwen \& G. Almevik

Mastering building conservation

G. Almevik

The built heritage sector in Portugal: Education in conservation and professionalisation

S. M. Genin \& P. Brum

Guidelines for quality of interventions in built cultural heritage in The Netherlands

S. Naldini \& M. van Hunen

Education and training as a means to boost skills and to increase territorial reputation:

The example of the Valtellina Cultural District in Italy

D. Foppoli, A. Konsta \& S. Della Torre

Real estate competencies in the built cultural heritage field

C. Boniotti, S. Della Torre \& A. Ciaramella 
Knowledge and skills associated to craftsmanship for built heritage conservation and rehabilitation: Case study - Historic Cairo

I. Waked, K. Van Balen \& D. Pini

\section{Obstacles and changes}

Adopting an integrated and holistic perspective for improving conservation of built heritage

G. E. Garcia \& F. Cardoso

Mapping professional practice challenges in built heritage

$J$. Gonçalves, R. Mateus \& J.D. Silvestre

Operative tools for new approaches towards urban conservation

S. Cardone

Obstacles and possible solutions for architectural heritage along the coastline of the

Baltic Sea in Latvia

D. Ržepicka \& A. Ziemelniece

Preservation of sacral heritage by learning from the past: Church building reconstructions in Hungary in the 1960 s and 1970 s

E. Urbán

Author index 


\section{Committees}

\section{ORGANISING COMMITTEE}

Prof. Koen Van Balen, University of Leuven, Belgium Dr. Aziliz Vandesande, University of Leuven, Belgium

Prof. Barbara Van der Wee, Barbara Van Der Wee Architects and University of Leuven, Belgium

Prof. Luc Verpoest, University of Leuven, Belgium

\section{INTERNATIONAL SCIENTIFIC COMMITTEE}

Tariq Al Murri, Architectural Conservation Consultant, Egypt

Omniya Abdel Barr, Egyptian Heritage Rescue Foundation, Egypt

Carolien Bolle, Centre de perfectionnement aux métiers du patrimoine-la Paix-Dieu, Belgium

Giorgia Cesaro, UNESCO-Project Officer, Jordan

Ali Davis, Historic Environment Scotland, Scotland

Barbara Fogarasi, Hungary

Hossam Mahdy, Architectural Conservation Consultant, Egypt

Monika Murzyn-Kupisz, Jagiellonian University, Poland

Silvia Naldini, TU Delft, The Netherlands

Terje Nypan, Riksantikvaren, Norway

Teresa Patricio, ICOMOS - Board member, Belgium

Eduardo Rojas, University of Pennsylvania, USA

Maria Eugenia Siguencia Avila, University of Cuenca, Ecuador

Dimitris Theodossopoulos, University of Edinburgh, Scotland

Nishant Upadhyay, UNESCO - Program Officer for Culture, India

Gabriella Garcia Velez, University of Cuenca, Ecuador 


\title{
Education and training as a means to boost skills and to increase territorial reputation: The example of the Valtellina Cultural District in Italy
}

\author{
D. Foppoli \\ Foppoli Moretta e Associati, Tirano, Italy \\ A. Konsta \& S. Della Torre
ABC Department, Politecnico di Milano, Milan, Italy
}

ABSTRACT: The paper explores the experiences on professionalism and lifelong learning carried out in the frame of the Cultural Districts project. This wide ranging programme was promoted by the Cariplo Foundation with the aim of producing new attitudes toward culture as a factor for local development. The project of the Valtellina Cultural District was established in 2010 in the Northern part of Lombardy (Italy) whose aim was to improve the awareness of the local community in the valorisation of cultural landscape and heritage, and of creating tangible and intangible networks. One of the focuses of the Valtellina Cultural District project was dedicated to improving cultural management, mobilizing cultural growth potential and contributing to employment and welfare creation. The case history is discussed through the analysis of the implemented educational and training activities and of their impacts both on the participants as well as the project as a whole, in terms of improvement of its reputation and setting out the basis for future developments. The involvement of human resources and local professionals was both a primary objective and an essential requirement of the territorial project. The general scope of these activities was to enhance capacity building in the field of cultural heritage and landscape and to ensure, over time, the presence of appropriate professionals to carry on the diverse operational tasks for protection and preservation. The learning environment created by the complexity of the project is deemed to be one of the reasons for its success in terms of engaging professionals in the enhancement of their own skills.

\section{INTRODUCTION}

The Cultural Districts project was promoted by the Cariplo Foundation as a wide area programme with the aim of producing new attitudes toward culture as a factor for local development (Barbetta et al. 2013, Cerquetti \& Ferrara 2015). From this perspective, the challenge was to overcome the common thought of associating valorisation with simply raising funds for conservation and to consider instead both its importance for the empowerment of local systems and its ability to enhance human/intellectual and social capital. In fact, in a long term vision, the activities related to conservation produce externalities, which can be transformed into value, through the improvement of professional skills and the strengthening of interpersonal attitudes, with reference to the models of the knowledge, economy and creativity (Della Torre 2015). This paper deals with this development of both hard and soft skills, which have been promoted and evaluated over the long-term experience of the project.
The programme has been financed with a $€ 20$ million grant since 2009 , supporting a total amount of almost $€ 60$ million investment and has been implemented in six different areas of the Lombardy Region: Monza and Brianza, Cremona Province, Mantua Po River Area, Mantua Gonzaga Palaces, Camonica Valley and Valtellina. Each project included several programmes, relating both to tangible and intangible heritage, according to the particular characteristics of the local heritage and its economic context. The diversity of these areas resulted in multiple projects, but their common aims of local development through the heritage sector and of sustainability in the long run unify them around the pivotal goal of building community through heritage (Della Torre 2015). The focus on the involvement of professionals and workers, although crucial for the Cultural Districts model, has not been described in detail and thoroughly discussed in the previous studies.

Three of these projects, Monza and Brianza, the Mantua Gonzaga Palaces and the Valtellina cultural districts, well exemplify the fulfilling of the 
initial expectations and needs and the working out of effective strategies. The first, the Monza and Brianza Cultural District, through investment in built heritage conservation works, involved various local stakeholders - from the public administration, the building sector, the innovative productive sector - with the aim of establishing a network of cultural and economic projects and the setting up of a sustainable management system for the local heritage (Canziani \& Moioli 2010, Moioli 2018). To achieve this purpose, two principal strategies were devised, the creation of a front office for the preventive and planned conservation and the development of training courses, in order to improve professional skills and stimulate a learning process (Della Torre \& Moioli 2012, Moioli 2013). Secondly, the enhancement and the integration of cultural and creative activities into heritage sites, increasing their public use and boosting innovation and local production (Moioli 2018).

As for Mantua and the "Regge dei Gonzaga" cultural district, the presence of outstanding monuments, in-scribed on the UNESCO World Heritage List, has played a key role for the development of a cultural economy model related both to the conservation programme and to the tourism industry. The strengths of this project can be found in promoting cooperation between the academic environment, industry and the public sector (Fanzini \& Rotaru, 2012). On the one hand, a centre for preventive and planned conservation was set up in the Mantua pole of the Politecnico di Milano university for supporting public administration in elaborating effective operational procedures and tools for built heritage management (Moioli 2014). On the other hand, training initiatives were promoted, such as the Masters Degree in preventive and planned conservation with numerous workshops in order to foster professional skills and transfer an innovative approach to the integration of the conservation and valorisation process of cultural heritage (Fanzini \& Moioli 2014).

The Valtellina Cultural District, on which this paper focuses, has evolved from a series of previous experiences in this area related to preventive and planned conservation of built heritage, starting from 2002 (Foppoli et al. 2008, Della Torre 2010, Foppoli \& Guiducci 2014). The knowledge and the professional skills acquired during that period were important for the development of the project and the achievement of its objectives. The projects carried out in this territory concentrated on the implementation of best practices in conservation through the involvement of local professionals with expertise in different disciplines. Moreover, special attention was paid to the creation of the necessary conditions for their continuity in the future through the development of education programmes and training courses as well as the encouragement of synergies and cross-border cooperation projects such as the "Preventive Planned Conservation in the Rhaetia Common Space" CPRE project (Foppoli et al. 2014).

From the brief description of the main strategies adopted by the three Cultural Districts mentioned above, the importance attributed to the development of a learning process at different levels should be clear. This kind of process involved various stakeholders, decision makers, experts and local professionals dealing with heritage as well as citizens and communities, indispensable factors for the exchange of benefits and externalities produced through the heritage sector. The constant collaboration between these three projects and the university, where the innovative approach to preventive and planned conservation was elaborated, created a learning community reinforced by exchanges of different kinds (Della Torre 2015).

This paper describes in detail the specific steps taken related to the education programmes and the training courses that were implemented in the territory of Valtellina. The analysis concerns firstly, the impacts and the results both on the participants and on the whole project and secondly, the current developments and the future steps referring to similar educational and training courses.

\section{THE VALTELLINA CULTURAL DISTRICT}

\subsection{Description of the geographical context}

Valtellina is an East-West trending alpine valley characterised by the presence of terraced vineyards that were built over recent centuries by terracing the steep, rocky mountain slopes using drystone walls. This terraced district is the largest wine-growing mountain terraced area in Italy, extending over 850 ha, representing $37 \%$ of the total Italian surface area of this kind (Fondazione ProVinea 2004).

The area, which in the past was densely populated, also boasts a remarkable built heritage, comprising characteristic villages, churches as well as civil and religious buildings with great symbolic value for the community. The unique character of this heritage can be attributed, in addition to the famous monuments, to a widespread fabric of small buildings scattered throughout the cities and the territory and to little hamlets of great landscaping value.

This heritage owes both its value and its fragility to its diffusion, for this reason it requires widespread maintenance works that are very difficult to coordinate and support. An additional weakness is due to recurrent floods or landslides caused by the lack of territorial maintenance, that, while being a mandatory requirement for cultural landscape, is extensively neglected in the Italian reality. 


\subsection{Building the landscape}

Valtellina territory is a perfect example of human transformation of the alpine area. In order to live there and carry out economic activity, the natural environment was radically transformed, developing in a cultural landscape that needs constant care and maintenance work to secure geological and environmental stability.

For this reason, the ability to build with dry stone was identified as one of the most significant peculiarities of the area. It features locally in a wide ranging variety of constructions: dry stone walls (Fig. 1) are essential structures in the support of slopes and to form areas suitable for cultivation; muracche (Fig. 2) are piles of stones used for cleaning the ground, providing protection from wind, improving the warming and creating ascending paths and baitelli (Fig. 3) are small constructions built entirely with dry stone with a "tholos" (aka false dome) technique that punctuate the territory especially in the confluence zone between Adda and Poschiavino creek, in so doing, culturally linking the territory of Valtellina with the nearby ValPoschiavo in Switzerland.

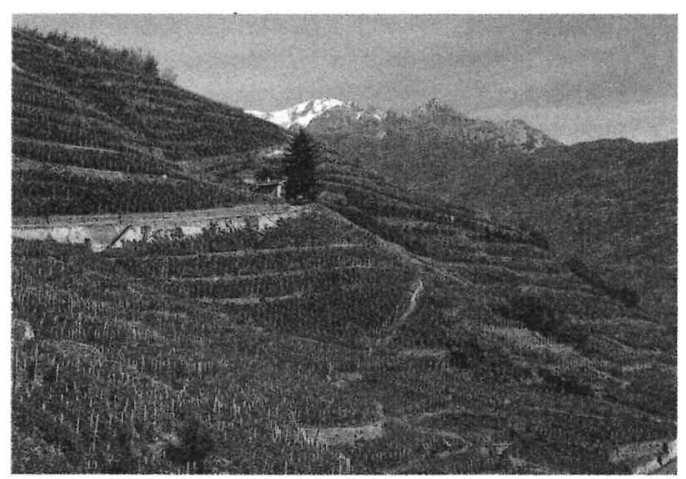

Figure 1. Drystone walls, fundamental elements of Valtellina cultural landscape.

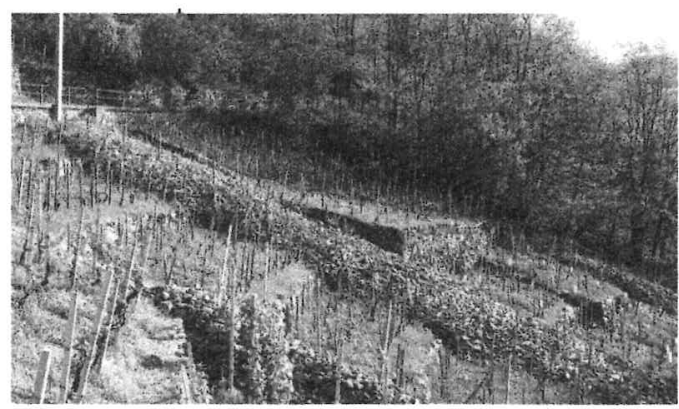

Figure 2. Piles of stones used for removing stones from ground, locally named muracche.

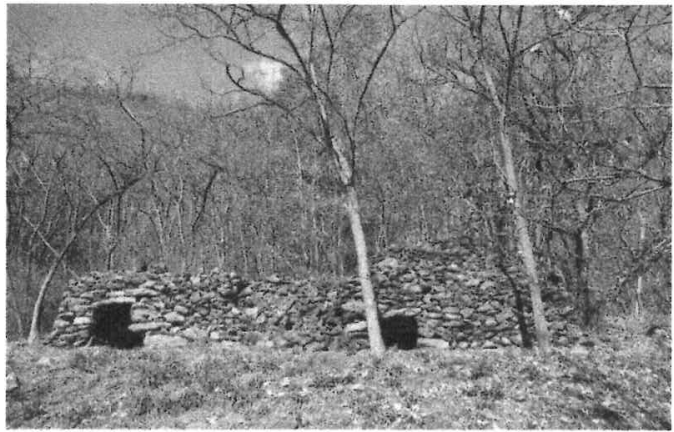

Figure 3. Small constructions built entirely with dry stone, with circular base and false-dome covering, locally named baitelli.

The outstanding element of alpine identity is the relationship between the human being and the territory, that is the capacity of man to turn an initially hostile environment into an environment suitable for habitation, so producing the necessary for his subsistence. This is the cultural heritage shared among all the inhabitants of the Alps, and in Valtellina this is made tangible by the presence of the wide Rhaetic terraced vineyards that are certainly one of the most evident features of the local landscape, confirming man's positive intervention on the environment and, at the same time, creating something of great aesthetic beauty.

The understanding of the importance of this cultural landscape and the recognition of its weaknesses has formed the base on which the Valtellina cultural district has established its objectives and has planned its strategies.

\subsection{Objectives and strategies of the Valtellina Cultural District}

The Valtellina Cultural District operates to consolidate the close relationship between landscape, traditional production and cultural identity, through an integrated and shared program for cultural heritage valorisation. It focuses on the enhancement of the historic settlements of the middle valley and the agri-food tradition that has modelled the landscape. Through knowledge of this heritage comes the development of long-term strategies.

The main initiatives in the program referred both to valorisation and networking and protection of the tangible and intangible cultural heritage. The tangible Work Packages includes "The Route of Terraces" (the wider one), restoration of S. Antonio cloister at Morbegno and Masegra Castle at Sondrio, setting up a circuit connecting palaces and castles at Tirano and "The Route of Water and Energy" in Alta Valtellina. The intangible WPs 
concern promotion of typical products through new technologies, research in archaeological and cultural heritage of the territory and conservation practice, as well as educational activities and training at various levels.

One of the most relevant projects of the Valtellina Cultural District was therefore the creation of a route for pedestrians and cyclists, $74 \mathrm{Km}$ long, in a zone placed on the Rhaetian terraced slopes, connecting religious and historical buildings, villages and hamlets, vineyards and rural farms of quality and interest (Di Capita \& Foppoli in press).

As it is evident, the District particularly focused on the valorisation of the terraced slopes, both on the tangible aspect, creating a path to allow their valorisation and, on the intangible one, making it one of the focus points for the training activities that have been developed.

\section{A KNOWLEDGE TRANSFER STRATEGY}

\subsection{Educational and training courses}

The educational and training activities developed in the framework of the Valtellina Cultural District, constitute one of the strategic lines adopted, so as to reach the objectives defined at the initial phase. Furthermore, evolution and improvement would be catered for during the growth of the project. The attention paid to these initiatives can be noticed by the planning of multiple courses addressing three main key stakeholder categories: students, professionals and farmers/craftsmen. Moreover, the projects focused on specific themes strictly connected to the general objectives pursued by the district, such as landscape, cultural heritage and planned conservation.

The first typology of educational courses were planned for students and aimed at a better understanding of the territory and the establishment of relationships with cultural heritage through the sharing of knowledge and the recognition of its values. Specific programmes were organised: for primary schools a "School curriculum for
Valtellina cultural heritage: landscape and its transformations" (promoted by the province of Sondrio) was developed; for secondary school teachers, a course on "Landscape and Cultural Heritage" was carried out, providing guidelines for knowledge and interpretation of landscape (promoted by the Fondazione Gruppo Credito Valtellinese); finally a "Tourist guide to The Route of Terraces", whose aim was to involve students as volunteering tourist guides, was arranged and scheduled.

The second typology of courses was dedicated to the training of local professionals in order to enhance their skills and to ensure the presence over time of appropriate figures who shall be able to carry on the operational tasks for protection and preservation.

Leading on from the stated observation that the peculiarities of the Valtellina territory are the cultural heritage and the landscape (or rather how cultural heritage is integrated into the landscape and how the landscape has been built around cultural heritage), the courses focused on two complementary topics: "Transformation of the territory, culture and local identity" and "Planned conservation of heritage building".

The first course was held in 2013-2014 and was divided into three modules, drawing attention to the following themes: "Terraced landscape", "Other Valtellina landscapes (woods, stone, water)" and "Management of cultural heritage and landscape". The course combined theoretical lessons with onsite visits within the territory, so providing further opportunity of collaboration with other professionals. The projects mainly contributed to the analysis and to the acquisition of knowledge about sustainable development models of the territory.

The second course was organised in collaboration with the Politecnico di Milano university and addressed the issues of the conservation/valorisation of cultural heritage, the relationship between intervention and management, the compatibility between traditional and innovative techniques, the digitalization of administrative and design procedures as well as the application of diagnostic and inspection techniques.

Table 1. Outline of training and educational activities developed within the frame of Valtellina Cultural District.

\begin{tabular}{llr}
\hline Activity & Promoter & Participants \\
\hline Master thesis & Politecnico di Milano & 4 thesis \\
Fellowships & Politecnico di Milano & 8 \\
80h Course "Inspection Technician" & ENAIP Lombardia & 10 \\
54h Course "Cultural landscape" & Local Development Foundation & 226 \\
36h Course "Preventive conservation" & Local Development Foundation & 164 \\
$40 \mathrm{~h} \times 3$ Course "Drystone walls" & Polo Poschiavo & $24+12$ \\
5 days Workshops and conferences & Local Development Foundation & 646 \\
\hline
\end{tabular}


The strategic value of these educational activities has gone well beyond what was initially foreseen, as the courses proved to be excellent opportunities for aggregation and discussion for the local professional community, to increase in reputation the Cultural District itself and to improve the information exchange locally (vs. province \& region) and beyond (vs. different Italian regions $\&$ foreign territories). So high was the success of the initiatives that a positive bond of collaboration with the neighbouring Swiss territory was created within the frame of a further cross-border ItalySwitzerland inter-regional cooperation programme 2014-2015 (CPRE project) that was agreed to strengthen the cooperation in the technical field between Valtellina and the Valposchiavo Region (Foppoli et al. 2014).

Many Swiss professionals have actively participated in both construction and management and teaching of the courses: so it was possible to complement and to develop to a further degree the scope of the Valtellina Cultural District, particularly in the field of analysis of the good practices of restoration intervention and implementation of preventive and planned conservation methodology.

Within the CPRE project, courses specific to the third typology of stakeholders were organized: farmers and workers operating in the construction sector. They were aimed at transmitting the knowledge related to the construction of dry-stone walls necessary for preservation of the cultural landscape and specifically to recover the craft skills, both in the construction and the maintenance of these walls. Moreover, the courses provided certificates of professional recognition, with validity both in Italian and Swiss territories: this is outstandingly advantageous because it recognizes the acquired skills on both sides of the border.

\subsection{Course impact evaluation}

A quantitative analysis of the degree of satisfaction and of effectiveness of the courses was carried out by Local Development Foundation with regard to the two courses for professionals: "Cultural landscapes" and "Planned Conservation". At the end of these courses, questionnaires were administered to the participants whose results are reported and commented in the following paragraph.

The overall judgment about both courses and their training content is more than fair for over $98 \%$ of the participants. Regarding the course "Programmed conservation", more than $94 \%$ of the sample considers the teaching methodology good/excellent. In respect of the training/informative effectiveness of the visits, the judgment is more than fair for almost $92 \%$ of the participants; the judgment about the teaching material is more than fair for almost $90 \%$ of the sample. The completeness of the courses, with respect to the key topics, was assessed too: the judgements vary from good to excellent for over $92 \%$ dealing with "the meaning of cultural landscape" and with a bit lower score for the other topics covered. For the "Programmed conservation" course, the judgements vary from fair to excellent, again featuring similar scores.

As for the overall impact of courses on the project, they have been seen to fully respect the objectives previously set out in terms of awareness and knowledge increase of local professionals concerning the discussed topics. They were, nevertheless, also an opportunity to bring the numerous participating lecturers into contact with local professional associations, with the aim of stimulating effective collaboration. The lecturers involved, mostly coming from outside the province, brought new and innovative experiences. An effective added value of the course was the opportunity to present the territory and the current operations to the lecturers, who were favourably impressed. In some cases, this allowed the development of subsequent joint activities, e.g. the adhesion to the ITLA (International Alliance for Terraced Landscape), which was activated within the frame of meetings developed during the lessons of the course and which will be discussed in the following chapter.

Furthermore, the collaboration with the professional associations was very positive. It guaranteed excellent feedback to the organization in terms of increased skills and a large number of participants. This collaboration has helped to increase the reputation of the Local Development Foundation as a cultural leader and of the Cultural District/CPRE activities in general.

Moreover, the collaboration with the Swiss partners was fundamental and productive. On the one hand Swiss technicians participated in the courses and on the other the involvement of numerous Swiss lecturers allowed a positive exchange of opinions.

\subsection{Conferences and publications}

In addition to the training courses, various seminars, conferences and publications were organised as a means of knowledge dissemination. We will mention here only the organisation of the international conference "Valtellina and Valposchiavo look beyond-Dialogue on the planned conservation of cultural and landscape heritage" that was held on 27-29 November 2014. It was organized in collaboration with important research institutions and protection agencies both in the Lombardy region (Politecnico di Milano, Superintendence for Architectural Heritage of Milan, Superintendence for Archaeological Heritage of Lombardy) and in the Graubunden Canton (Monuments Service of Chur). 
The conference was attended by more than 200 people. Thirty experts were invited both from Italy (Rome, Genoa, Trento) and from abroad (Switzerland, France, Slovenia, United Kingdom, Belgium) with the aim of ensuring an appropriate international atmosphere and to stimulate the comparison between actions carried out within local projects and national/international best practices, as well as highlighting the present and future contribution of Valtellina and Valposchiavo to the international research community.

\section{OUTCOMES}

\subsection{Current developments}

The most evident results of the training activities carried out consisted in clear and effective growth of territorial planning capacity. After the completion of the Cultural District activities, a number of further projects were presented in order to develop the themes proposed; they often reached high scores in the evaluation and allowed access to significant grants. This has enabled the development of further steps related to the issues undertaken. It is also significant that these actions have been developed by subjects who have benefited from the training activities of the Cultural District, even if sometimes they are not direct partners: this is proof of the effectiveness of the training and communication campaigns carried out.

A first example of the synergies created refers to the activity of "caring for the landscape"; it is the development of 2014's "\# More Positive Signs" programme, developed from the Cariplo Foundation call, "Welfare in action". This project was set up by both public entities and social cooperatives; in 2015, it was funded and it is currently underway.

It originated from the observation that during the period 1961-2007 in the Valtellina territory, a marked reduction of terraced vineyards (minus $40 \%$ ) and pastures (minus 46\%) and the increase of neglected rural areas (plus 27\%) can be noticed. Moreover, during the last twenty years, data regarding the economic conditions in the specific area shows a rapid rise of poverty (plus 25\%). Therefore, the project, mainly aimed at the welfare sector, develops the idea that it is possible to face both social and territorial weaknesses by creating working opportunities in the maintenance of abandoned land.

In detail the project was developed in three Work Packages. The first WP (2015) concerned the maintenance and valorisation of abandoned paths at high altitude: as a result, 66 paths were recovered $(116 \mathrm{~km}$ in global length) and $600 \mathrm{~m}$ of dry stone walls reconstructed, by creating 5 new stable jobs and allocating $€ 256.000$ total gross wages for the benefit of local families.

The second WP (2016) addressed the recovery of abandoned marginal areas owned by the municipalities for social purposes. Ten sites were selected for three-year projects, and four of them have already been completed (Sondrio, Ponte). In this case, 180 people were involved, 5 new stable jobs were created and $€ 140.000$ total gross wages were allocated.

The third WP, which is still in progress, aimed to recover a large abandoned terraced area through productive re-planting of grapevine. It has been carried out in partnership with the municipality of Castione and a private company: as a result 3.5 ha terrace areas were recovered, by allocating (data updated at February 2018) $€ 92.000$ gross wages and creating 7 new stable jobs.

A second interesting example is the "MigliorArTi-Seismic Improvement of the Arcari Library at Tirano" project, dealing with planned conservation programs. It was submitted by the municipality of Tirano to the 2017 Cariplo Foundation call "Hazard for Cultural heritage". This municipality was indeed a partner in the Valtellina Cultural District and also in the CPRE project and moreover the technicians of the Municipal Technical Office took part in the training activities described above. Therefore, the municipality was able to share with the Cultural District the approach to the Preventive and Programmed Conservation. Accordingly it recognized the great articulation of its own real estate classified as cultural heritage (churches, palaces, but also some school buildings that date back to the beginning of the nineteenth century) and therefore elaborates a project for the evaluation of seismic vulnerability and the reduction of seismic hazard for one of its own most visited properties: the civic library.

This project implements knowledge, conservation and valorization; it experiments innovative design methods through B.I.M. (Building Information Modeling) thus proposing a reproducible prototype model that can also be applied to the entire real estate assets of the municipality, but even more to other municipalities. That's why the project was considered worthy of being funded and is currently underway, primarily in terms of historical, stratigraphic, surveying and structural diagnostics analysis. A B.I.M. model has been implemented and it is currently in processing for developing the structural model aiming to assess the seismic vulnerability and to retrofit the building in the static and seismic field. It will subsequently be used to manage the conservation plan for the overall building. 


\subsection{Future actions}

The educational activities of the Valtellina Cultural District allowed for the contacting of international associations engaged in the promotion of terraced territories and dry stone constructions. In fact, the importance of dry stone constructions for the protection of the natural environment, the management of land and the preservation of local traditions has been recognised over the last years at an international level.

It is important to highlight here the already mentioned adhesion of some territorial foundations (Local Development Foundation and ProVinea Foundation) to the International Terraced Landscape Association (ITLA), which took place during the training programmes in the frame of the projects. This association brings together institutions, universities and farmers, so as to reinforce knowledge exchanges and common projects about terraced landscape. During the last years it organised three international congresses in different countries (2010, China; 2014, Peru; 2016, Italy) and has already planned a fourth meeting in Spain for 2019.

The ITLA association gathered the international proposal (carried out by a joint partnership of Cyprus, Croatia, Spain, France, Greece, Italy, Slovenia, Switzerland) to apply "Art of dry stone: knowledge and techniques" in the Representative List of the UNESCO Intangible World Heritage. This is a relevant mean of underlining this heritage and foster awareness about its importance, both in planning landscapes and forming identities.

The fact that the above described courses allowed the Valtellina territory to have the opportunity to be aware of the international level of relevance of the issue of the protection of drystone walls and consequently to join the partnership of the above mentioned proposal, is highly significant. This is a good basis both for developing further projects and for researching of further grants within an internationally based partnership.

\section{CONCLUSIONS}

The Valtellina Cultural District proved able to both sustain local development through cultural heritage valorisation, based on a deeper understanding of the places, and to strengthen the links between the territory and the people.

The cultural identity of a territory can only be improved through a process of knowledge and correct educational programmes. Within the Valtellina Cultural District, these activities were aimed at students, professionals, craftsmen and farmers so as to obtain a widespread and shared knowledge of the value of the landscape and cultural heritage.
This project also focused on the problem of maintenance of dry-stone structures, one of the most characteristic of this specific alpine landscape. Around this issue it was possible to join firstly the neighbouring Swiss territory, then the Italian ITLA association and finally a global European interest resulting in the application of "Art of dry stone: knowledge and techniques" as UNESCO Intangible World Heritage. This is a good case history of the virtuous path from the identity of the territory to the increase of skills, to the increase of reputation.

\section{REFERENCES}

Barbetta, G.P., Cammelli, M. \& Della Torre, S. (eds.) 2013. Distretti culturali: dalla teoria alla preatica. Bologna: Il Mulino.

Canziani, A \& Moioli, R. 2010. The learning-based Cultural District and the Monza and Brianza case. Learning from cultural heritage. In: M. Mälkki \& K. Schmidt-Thomé (eds.), Integrating aims. Built heritage in social and economic development: 157-159. Helsinki: Helsinki University of Technology, Centre for urban and regional studies publications.

Cerquetti, M. \& Ferrara, C. (2015). Distretti culturali: percorsi evolutivi e azioni di policy a confronto. Il Capitale culturale, Studies on the Value of Cultural Heritage, 3: 137-163. Available at: http://riviste. unimc.it/index.php/cap-cult.

Della Torre, S. 2010. Learning and unlearning in heritage enhancement processes. ESA Research Network Sociology of Culture Midterm Conference: Culture and the Making of Words. Available at: https://ssrn. com/abstract=1692099 or http://dx.doi.org/10.2139/ ssrn. 1692099.

Della Torre, S. 2015. Shaping tools for Built Heritage conservation: from architectural design to program and management. Learning from "Distretti Culturali". In: K. Van Balen \& A. Vandesande (eds.), Community involvement in heritage: 93-101. Antwerp: Garant.

Della Torre, S. \& Moioli, R. 2012. Designing an active monitoring system: the planned conservation project in Monza and Brianza province. In: S. Mendes Zancheti \& K. Similä (eds.), Measuring Heritage Conservation Performance: 142-147. Olinda and Rome: CECI and ICOMOS.

Di Capita, F. \& Foppoli, D. (in press). The Route of Terraces in Valtellina: Community involvement and tourism for the enhancement of cultural landscape. In: Proceedings of $3 \mathrm{rd}$ World meeting on terraced landscape, Venice - Padua.

Fanzini, D. \& Rotaru, I. 2012. The Italian Cultural District as a model for sustainable tourism and territorial development. Journal of Tourism Challenges and Trends, 2(2): 11-34.

Fanzini, D. \& Moioli, R. (eds.) 2014. Il Master in conservazione preventiva e programmata per la valorizzazione dei beni culturali del Distretto Le Regge dei Gonzaga. Milano, Firenze: Politecnico di Milano, Nardini Editore. 
Foppoli, D., Giudici, P. \& Zucchella, A. 2008. I Beni Culturali come strumento di crescita per il territorio: Il progetto Pieve di Mazzo. In: Atti del convegno Cultura e Territorio - Beni e Attività culturali: valorizzazione e indotto in prospettiva europea: 50-58. Pavia: Franco Angeli.

Foppoli, D. \& Guiducci, S. 2014. Esperienze di Conservazione Programmata in Valtellina. Kermes quaderni: 247-254. Firenze: Nardini.

Foppoli, D., Menghini, G. \& Zanolari, E. 2014. Preventive conservation: an opportunity of cooperation in the heart of the Alps. In: S. Della Torre (ed.), Proceedings of the International Conference Preventive and Planned Conservation Monza - Mantova, 5-9 May 2014, vol. I La strategia della Conservazione programmata, Dalla progettazione delle attività alla valutazione degli impatti: 85-96. Firenze: Nardini Editore, pp.
Fondazione ProVinea, 2004. La zona dei vigneti terrazzati del versante retico della Valtellina come patrimonio Mondiale dell'UNESCO. Sondrio: Fondazione ProVinea.

Moioli, R. 2013. Lo sportello per la conservazione Preventiva e programmata: processi e progetti per l'attuazione. Rivista dell' Istituto per la Storia dell' Arte Lombarda, 9: 29-44.

Moioli, R. 2014. Preventive and Planned Conservation. Towards an economic approach. In: Fanzini, D., Casoni, G and Bergamini, I. (eds), Enhancement of cultural heritage and local development: 133-145. Santarcangelo di Romagna: Maggioli.

Moioli, R. 2018. The Spinning model in Sulbiate: A place for changes. In: K. Van Balen \& A. Vandesande (eds.), Innovative built heritage models: 151-160. Leiden: CRCPress/Balkema. 